\title{
Endocardial fibroelastosis
}

INSERM

\section{Source}

INSERM. (1999). Orphanet: an online rare disease and orphan drug data base.

Endocardial fibroelastosis. ORPHA:2022

Endomyocardial fibroelastosis is a cause of unexplained childhood cardiac insufficiency. It results from diffuse thickening of the endocardium leading to dilated myocardiopathy in the majority of cases and restrictive myocardiopathy in rare cases. It may occur as a primary disorder or may be secondary to another cardiac malformation, notably aortic stenosis or atresia. 